\title{
BIOFUEL PRODUCTION TECHNOLOGY FROM BIOENERGY CROP-ALGAE BIOFUEL
}

\author{
Sandeep Gupta \\ School of Chemical Engineering, \\ Galgotias University, Greater Noida, \\ G.B. Nagar, U.P., India
}

\author{
Hashibul Hoque \\ Department of Mechanical \& \\ Automation Engineering, Maharaja \\ Agrasen Institute of Technology, \\ Rohini, Sector 22, Delhi, India
}

\author{
Sagar Baul \\ School of Chemical Engineering, \\ Galgotias University, Greater Noida, \\ G.B. Nagar, U.P., India
}

\begin{abstract}
The continually rising populace and overwhelming burden on farming terrains for expanding business crops the huge scope and financially feasible biofuel creation ashore appears to be a test to meet the colossal and expanding worldwide vitality request. The utilization of bioenergy crops for creating biofuels is are penny idea and loaded with possibilities. Green growth shows promising outcomes in turning out to be hotspot for biofuel. It considered as manageable, sustainable and successful biomass and bio-powers and to satisfy the high biomass requests for biofuel creation, it is significant significance to create achievable advances to empower financial, effective and high thickness development of green growth. Green growth can be developed in either open or shut frameworks within the sight of supplements and light force Algal biomass is utilized in the creation of biofuels like biodiesel, bioethanol, bio-butanol and bio-hydrogen and so forth.
\end{abstract}

Keywords: Depletion of Fossil Fuels, Renewable, Algae, Biofuel, Biomass.

\section{INTRODUCTION}

Universally interest for vitality is definitely expanding because of the development of total populace and the progressions of the solace of human life. Expectedly, petroleum derivatives have been the principle wellspring of overall vitality. Be that as it may, the proceeded with utilization of petroleum derivatives is currently generally considered as impractical. This prompts both exhausting non-sustainable power source holds and numerous natural issues identified with non-renewable energy source burning.

As of now, nations including USA and Brazil produce biodiesel and bioethanol utilizing human evolved way of life crude materials, for example, corn, sugarcane, sugar beet, sorghum and wheat. Be that as it may, the evolved way of life based biofuel businesses are getting expanded analysis. This is because of the contending requests of indistinguishable hotspots for human utilization from food. As another option, there are different sorts of biofuels starting from non-food feedstock, for example, agrarian squanders, metropolitan squanders, microalgae and other microbial sources. The original bio-powers have been popularized around the world, its manageability have been examined due to its ruinous consequences for nature and environment. In addition, this sort of bio-fuel can't fulfill the world vitality need in view of rivalry with materials which are utilized as creature feed and human food. Such issues have prompted appearance of the Second era of bio-fills. Second era biopowers are created from squander and lignocellulosic feedstock. Their main advantage over original feedstock is to not having rivalry with food/feed supplies. Also, they offer higher bio-fuel creation yield and they require lower land for developing. Regardless of these favorable circumstances over the original of bio-energizes, they have some genuine downside of not being financially suitable everywhere scales .Genetically changed microorganisms, for example, microalgae, yeast, parasites and cyanobacteria are the fourth era bio powers. $\mathrm{CO} 2$ could be straightforwardly changed over to fuel by these microorganisms. Microalgae are infinitesimal cells or chains of cells which live in new or saline water and can change over carbon dioxide, water and daylight into biomass through photosynthesis. The development rate and oil substance of microalgae are quicker and higher than large scale green growth.

In addition, they have Third era of bio-energizes doesn't have the hindrances of past age of bio-fills. They are gotten from algal biomass and are the most encouraging elective asset

These new potential elective feedstock can be utilized for huge scope age of bio-fuel without upsetting the earth. Consequently, they can defeat disadvantages related with first and second bio-fuel age. Their profile fuel creation rate is a lot higher than different sorts of biopowers because of their higher develop rate. Besides, they can develop in non-arable terrains, and they have no cover with food gracefully .Production expenses and cost proficiency of algal last items are high and low, individually. In this manner, regardless of referenced positive perspectives, green growth have not been created on a huge business scale. The move to biofuel options have in the ongoing years turned into a significant issue of enthusiasm for the world .Their natural maintainability, plenitude, dispersion example and preparing practicalities have represented their solid possibilities as fills for what's to come. Like the non-renewable energy sources, biofuels can be determined in the fluid, strong and vaporous structures for different family unit and mechanical applications. They can be used in existing framework and vehicles without the requirement for re-design. They are not related with decimation to marine living beings since biomass would be delivered and prepared into energizes utilizing $100 \%$ coastal framework. So also, the issue of gas flaring can be killed totally. In any case, the utilized especially because of their favorable circumstances that incorporate accessibility, reusability and built up possibilities in biogas, biodiesel and bioethanol creation from biomass substrates. Post-liquefaction valorization of green growth based biooil was additionally significantly secured. The capacity of the heterogeneous impetus frameworks to deliver hydrocarbon mixes (counting the gas scale BTEX aromatics) that are in the fills go was the focal point of the paper. The paper all the while distinguished and talked about regions requiring further examinations to support 696 
different analysts in the field. Bioenergy is a sort of sustainable power source that is gotten from natural sources where biomass is utilized legitimately as fills or changed over into fluid or gas structure. The normal kinds of biomass used to deliver bioenergy incorporate woodland trees, agro-backwoods buildups, harvests and sea-going plants. The greater part of the natural sources are singed or extricated so as to change over the feedstock into heat vitality and force for mechanical, private and business utilizations. Albeit sustainable power source, for example, sun oriented, hydro and wind vitality has been used for a considerable length of time, the ideas of climate conditions that impact vitality creation have regularly been a worry.

With the utilization of bioenergy, the vitality creation will be sensible and can be delivered by the necessities as the procedure is autonomous of climate condition. One of the bioenergy, to be specific biofuels, is researched seriously because of its inexhaustible, perfect and natural agreeable properties. Biofuels basically comprise of bioethanol, biogas and biodiesel which are created through various procedures, for example, trans esterification, maturation, gasification et cetera. For the original of biofuel, starch crops like sugarcane, maize, sugar beets, and wheat were generally utilized as feedstock for bioethanol while rapeseed and soybean were utilized to create biodiesel. Starch[5] rich harvests were picked as they contain high measure of sugars while biomass picked for delivering diesel is inferable from their oil improvement properties. In spite of the fact that the feedstock of original's biofuel is inexhaustible and has limited ozone harming substances emanation, the use of food crops as an asset of biofuel has caused huge effect on the estimating of food crops which influence the nations experienced food lack. The objective of second era biofuel's feedstock are for the most part non-food crops, for instance tobacco seed, Jatropha, and creature fats which had the option to defeat the rising food value issue yet the impracticality and low yield of items are bothersome.

So as to conquer the issues looked in the first and second era of biofuel, an appropriate feedstock for biofuel creation must not be serious with food items. Furthermore, the feedstock ought to be effectively accessible and supportable. In this manner, the potential feedstock for third era biofuel found by scientists is green growth. In contrast to earthly photosynthetic plants, green growth are a good asset for biofuel as they are excluded from higher food estimating and effect on biodiversity. The high accessibility of green growth is seen because of the fast development pace of green growth and their capacity to make due in cruel conditions. Aside from that, the inexhaustibility, manageability and reproducibility of green growth have become their focal points over the first and second era feedstock as biofuel asset. This survey centers around the bioprocessing plant and biofuel created utilizing algal biomass. Current innovations in delivering green growth based biofuel and the difficulties looked by green growth based biofuel are talked about in this survey too.

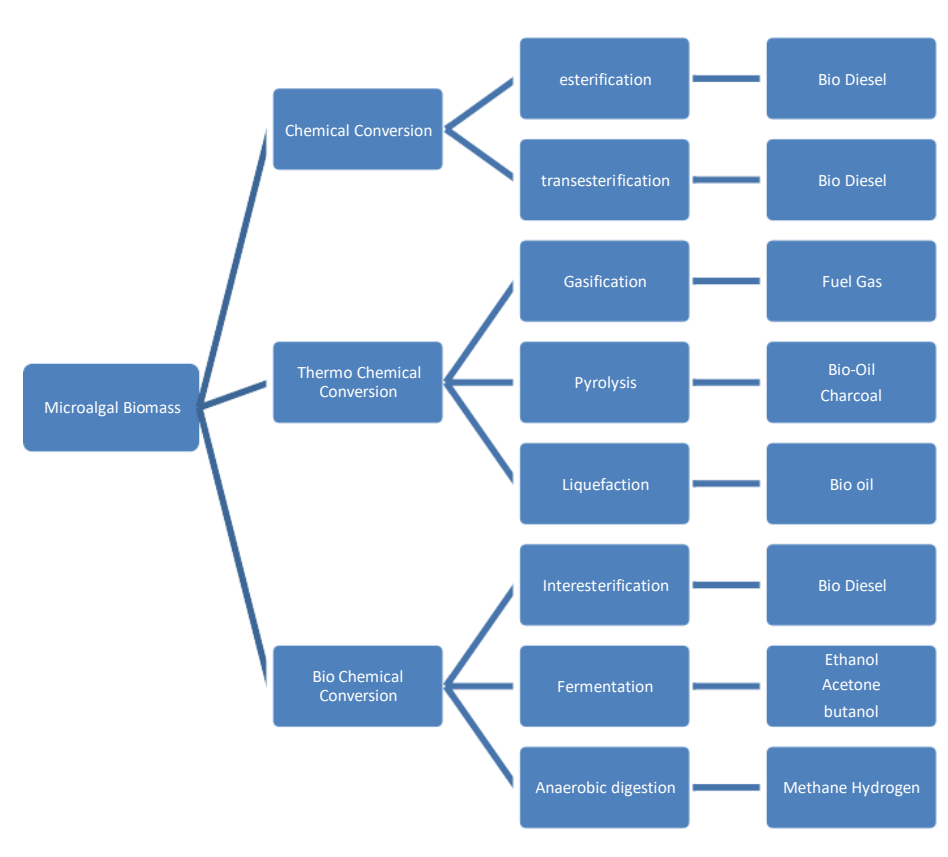

Brennan L, Owende P. Biofuels from microalgae. Impracticality and constant depleting of non-sustainable petroleum products have started significance of inexhaustible fuel sources. What's more, expanding worries about a worldwide temperature alteration because of non-renewable energy source utilization and expanding fuel cost had prompted investigate elective and sustainable power source. At this point, biofuel came to spotlight to deflect green-house vaporous discharges and to substitute petroleum product. Biofuel is a nonpoisonous, elective, sustainable, eco-accommodating fuel created from different feed stocks. Among the feed stocks, microalgae show enormous potential in supplanting petroleum derivatives to guarantee vitality security, and to forestall the ecological dangers over the globe. This could be because of the high biomass delivering capacity of microalgae over earthly harvests, and furthermore microalgae require $\sim 49$ - multiple times less zone contrasted with soybean crops.

Notwithstanding fuel creation from microalgae, different nonvitality items or high worth items can likewise be extricated from microalgae, which are viewed as commercially valuable. Microalgae contain three significant macromolecules specifically sugar, protein, lipid, and in this manner they have for quite some time been utilized as a promising biomaterial for the creation of different mechanically significant CO3 items. In light of the preparing strategies, various items could be acquired from the microalgal biomass.

The total or entire microalgal biomass can be changed into different bio-items through appropriate transformation strategies. Ongoing past, bio processing plant approach has been polished to change the microalgal biomass into energizes, items, and other worth included mixes. Further, microalgae can be utilized to treat squander water through phycoremediation and alleviate $\mathrm{CO} 2$ from the air to keep up natural maintainability. It is basic to give an extensive view on usage of green growth in different areas like fuel, food and condition. Thinking about the immense capability of green growth, creation of fuel or food items from different algal biomasses should be arranged to pick the relevant algal species. Along these lines, this survey is endeavored to concentrate comprehensively on the biofuel, 


\section{International Journal of Engineering Applied Sciences and Technology, 2020 Vol. 4, Issue 12, ISSN No. 2455-2143, Pages 696-707 \\ Published Online April 2020 in IJEAST (http://www.ijeast.com)}

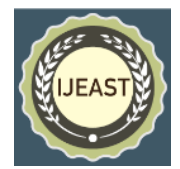

bio-items and bioremediation perspectives.

At first, use of distinctive feedstock for biofuel creation over the ages will be talked about and a few esteemed included items separated from green growth will be summed up. In the end, bits of knowledge on the ecological advantages of green growth will be depicted.

\section{ALGAE SPECIES}

As referenced before, green growth are a various group of photosynthetic eukaryotes species. The majority of these species are oceanic. Various kinds of green growth amass oil and lipids have a thickness lower than water. This lower thickness assists with their buoyancy in lakes and tidal ponds. More than 36,000 distinct types of green growth are accessible in the normal biological system. Green growth species can be named red green growth, green growth, earthy colored green growth, diatoms, blue green growth (prokaryotes) or dinoflagellates. A significant number of these green growth have discovered different useful uses including creature food, manure, pharmaceutical medications creation, contamination control, water treatment, colors, agar produce and as hotspot for bioenergy. In early research activities, culture frameworks of microalgae were examined in a point by point way as an option in contrast to protein hotspots for human utilization. As of late, the center has been moved to the utilization of microalgae refined for $\mathrm{CO} 2$ catch and biofuel creation. Microalgae can catch transmitted $\mathrm{CO} 2$ from an assortment of sources and can change over $\mathrm{CO} 2$ into biomass with the assistance of daylight and photosynthesis. In addition, microalgae created can be additionally handled to fabricate biofuels. Microalgae can develop quickly. Microalgae likewise can integrate and amass enormous sums (around 20\% - half of dry weight) of nonpartisan lipid put away in cytosolic lipid bodies. Accordingly, a fruitful and monetarily feasible green growth put together biofuel industry principally depends with respect to the determination of suitable algal strains. One can without much of a stretch notification from this table a large portion of the green growth contain enormous measure of proteins, predominantly enzymatic proteins or unrefined proteins.

These proteins, chiefly amino acids, give great supplements generally found in nourishments and feeds for creatures. To develop the green growth species, carbon dioxide, water, supplements and reasonable temperature control are required. Wastewater contains critical measures of supplements that are appropriate for green growth development. As can be found in this table, Chlorella vulgaris and Phormididium laminosum are two principle kinds of green growth species that have been broadly examined. Different species considered incorporates Anabaena doliolum, Chlorella emersonii, Chlamydomonas reinhardtii, Scenedesmus bijugatus and Scenedesmus sideways. So as to accomplish the most extreme profit by microalgae culture, it is fundamental to focus on the determination of sufficient species or strains. Microalgae culture comprises of a solitary explicit strain exactly chose for creating the ideal item and the most useful result of the way of life process. It is likewise critical to see that necessary culture conditions are

(a) water media at the sufficient $\mathrm{pH}$ and temperature,

(b) important contained supplements and (c) dosed in a controlled way in nearness of daylight. So as to guarantee the correct development of microalgae, the necessary nutrients must be provided.

Supplements can be ordered into the accompanying classes:

(i) carbon source from $\mathrm{CO} 2$,

(ii) energy source from daylight,

(iii) nitrogen source (for example alkali, nitrates) from wastewater or other culture media,

(iv) other minerals from culture media and possibly included nutrients.

\section{MICROALGAE CULTIVATION SYSTEM- PHOTOBIOREACTOR TECHNOLOGY}

There is in the logical writing, a wide scope of the microalgae development frameworks announced. These microalgae culture frameworks vary mostly relying upon
(a) the cost,
(b) the kind of wanted items,
(c) the wellspring of supplements and
(d) the $\mathrm{CO} 2$ catch.

3.1 The way of life frameworks are commonly ordered by their structure conditions as "open" or "shut" frameworks. The "open" frameworks are outside offices that incorporate lakes, tidal ponds, profound channels, shallow circling units and others, while the "shut" frameworks are vessels or cylinders with dividers made of straightforward materials situated in outside offices under daylight light or indoor offices under counterfeit illumination. Because of their specialized unpredictability, photobioreactors have been considered for quite a while as the direct opposite of open lakes innovation. It is as of late and because of the operational challenges with open lakes that shut bioreactors are being considered as giving helpful strategies for algal mass culture. The expanding enthusiasm for this innovation is driving algal culture towards extraordinary improvements including snappy specialized advancement. By and large, advanced photobioreactors are increasingly adaptable however such reactors are costly and hard to work and control. A few examinations recommend, in any case, that the utilization of photobioreactors is a progressively attainable and reasonable alternative, particularly for the evacuation of $\mathrm{CO} 2$, and for wastewater treatment applications.

\subsection{Components of railway wagon}

Open framework Open lakes have for quite some time been utilized for huge scope microalgae development given their straightforward development and moderately simple activity. Such development frameworks can be delegated

(i) natural water frameworks, for example, lakes, tidal pond, lakes and

(ii) artificial water frameworks, for example, fake lake, tanks 


\section{International Journal of Engineering Applied Sciences and Technology, 2020 Vol. 4, Issue 12, ISSN No. 2455-2143, Pages 696-707 \\ Published Online April 2020 in IJEAST (http://www.ijeast.com)}

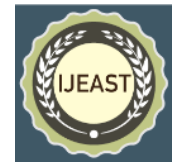

and compartments.

Contingent upon the applications, various shapes, sizes and sorts of open frameworks (disturbed, slanted and others) have been explored. It shows different lakes that have been accounted for in the specialized writing. Among them, nonblended lakes are the most conservative, being the less difficult to oversee. Business non-blended lakes are worked in common water lakes with not exactly $50 \%$ of meter top to bottom. Notwithstanding, this kind of lake is exceptionally restricted in its applications given that green growth species can't get by under as often as possible poor development conditions. One can record, notwithstanding, a development of open frameworks, with this being the aftereffect of attempting to address blending issues in lakes, forestalling green growth sedimentation and improving light usage. Accordingly, in open lakes, blending is of extraordinary centrality with this affecting working expenses and efficiency. Critical requirements likewise influence open lake activity. For example, in high cell-thickness culture frameworks, light angles inside the green growth can be only sometimes forestalled, given media, light assimilation and cell concealing. Besides, biomass efficiency isn't just reliant on the aggregate sum of sun oriented vitality infiltrating the way of life surface, yet additionally on the amount of vitality accessible at the cell level. This prompts different conceivable structure systems and working parameters, for example, 'light system' and 'light per cell' as proposed by Richmond. Given all the portrayed issues, the beneficial usage of open culture frameworks has been constrained to extraordinary cases, for example, creation of fortes nourishments with guaranteed medical advantages. For instance, creation costs in Japan have been in the scope of $10-20 \$ / \mathrm{kg}$ for Chlorella. In any case, in open lakes, until today, just a couple of types of microalgae have been found to develop well at a business scale.

3.1.1. Unstirred lakes: Unstirred lakes give an efficient and basic path for working a lake office. Unstirred lakes are industrially utilized for some microalgae species societies, for example, Dunaliella salina. Borowitzka et al. announced that these kinds of huge unstirred open lakes are of basic development. For instance, regular water lakes with not exactly a large portion of a meter top to bottom can be utilized. Comparative little lakes are shallow water surfaces secured with plastic movies. Lee announced that in SouthEast Asia, more than $30 \mathrm{t}$ for each time of dried microalgae biomass were gathered from unstirred normal lakes. Unstirred open lakes are, in any case, constrained to developing microorganisms under poor natural conditions being presented to the simultaneous development of protozoa, microscopic organisms and infections.

3.1.2. Raceway lake: The most well-known open culture framework being as of now utilized is the "mixed oar wheel open lake" or "raceway lake". This kind of open lake is normally shallow and usually in the middle of 15 and $25 \mathrm{~cm}$ inside and out. Raceway lakes are typically developed as either a solitary channel or as gatherings of channels that are worked by consolidating singular raceways. In raceway lakes, the profitability of the biomass has been demonstrated to be as high as $60-100 \mathrm{mg}$ dry weight. Raceway lakes are for the most part utilized for the business refined of four types of microalgae: Chlorella sp., Spiriluna platensis, Hematococcus and D. salina. Various structures of raceway lakes, particularly the oar wheel blended sort, have been utilized financially throughout the most recent 30 years. The dissemination of the refined media in the raceway lake circle is helped by an oar. This flow creates the water speed required to keep away from the testimony of settling cells or the conglomeration of cells through flocculation. Numerous lakes are worked with a fluid speed of in excess of $30 \mathrm{~cm} / \mathrm{s}$. Much of the time, challenges are experienced with strong statement in stale zones. In raceway lakes, biomass groupings of up to $1 \mathrm{~g}$ dry weight/L and 60-100 mg dry weight/L d productivities are ordinarily gotten.

Roundabout lake Circular lakes (focal turn) have essentially been utilized for huge scope development particularly in South-East Asia for the way of life of Chlorella. Roundabout lakes are the most established huge scope green growth development open lakes. The profundity of these lakes is around $25-30 \mathrm{~cm}$. Microalgae are normally developed in solid roundabout lakes up to $45 \mathrm{~m}$ in measurement, with fomentation by a turning arm (looking like a clock dial with the second pivoting hand going around). A 20-30 $\mathrm{cm}$ thick layer of inorganic supplement arrangement with green growth, presented to daylight and rose by $\mathrm{CO} 2$, is persistently moved by methods for paddle wheels.

3.1.3. Limitations of open pond systems The major limitations in open systems include the following:

(a) poor light utilization by the cells,

(b) significant evaporative losses,

(c) limited diffusion of $\mathrm{CO} 2$ from the atmosphere, and

(d) large areas of land are required.

What's more, tainting is another serious issue of open frameworks with enormous scope microalgal creation. Undesirable green growth, form, organisms, yeast and microorganisms are the normal natural contaminants regularly found in these open frameworks. To conquer the above restrictions, basic plastic covers or green houses over the open lakes have been proposed. Plastic covers additionally permit augmentation of the developing time frame. A porous plastic spread additionally encourages move and flexibly of carbon dioxide and the support of gentle temperatures over night hours. It has been accounted for that the covering of open lakes gives an improvement of biomass productivities. Sadly, be that as it may, sullying issues despite everything stay uncertain. Notwithstanding that, capital costs, upkeep and overheating make open lakes secured with translucid plastics is unrealistic with this being particularly valid for enormous size units.

3.3 Closed system: Shut frameworks, for the most part known as photograph bioreactors, can address a portion of the issues related with open lake frameworks. The significant points of interest of the shut frameworks are as per the following:

(a) minimization of water vanishing and

(b) reduction of the development of serious algal weeds, predators and pathogens that may slaughter the ideal microalgae. It is critical to recognize that in spite of the fact that photobioreactors fundamentally decrease the development of serious algal weeds, they can't totally take out the development 


\section{International Journal of Engineering Applied Sciences and Technology, 2020 Vol. 4, Issue 12, ISSN No. 2455-2143, Pages 696-707 \\ Published Online April 2020 in IJEAST (http://www.ijeast.com)}

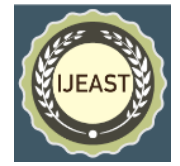

of contaminants. A definite correlation of various shut photobioreactor frameworks and their biomass profitability.

Tubular photobioreactor: Given the few referenced drawbacks of open frameworks, shut frameworks have been getting extraordinary consideration. A few rounded photobioreactors have been examined and created since the spearheading work of Tamiya. Rounded photobioreactors are made with straightforward materials and are set in outside offices under daylight light. A gas trade vessel where air, $\mathrm{CO} 2$ and supplements are included and $\mathrm{O} 2$ is evacuated is associated with the central power source. One of the fundamental attributes of these development vessel plans is their enormous surface territory per unit volume. This is done to augment introduction of the microalgae to daylight. Cylinder sizes are commonly under $10 \mathrm{~cm}$ in width to make sure about daylight entrance. In an ordinary rounded microalgae culture framework, the medium is coursed through the cylinders, where it is presented to daylight for photosynthesis. The medium is flowed back to a repository with the assistance of a mechanical siphon or an airdrop siphon. The siphon additionally assists with keeping up a profoundly tempestuous stream inside the reactor, keeping the algal biomass from settling. A small amount of the green growth is generally gathered after it circles through the sun oriented assortment tubes, making the framework a constant activity. Until today, the greater part of the rounded photobioreactors, concentrated in nearness of counterfeit light have been created at little/research center scale (0-20 L limits). There is, in this regard, a predetermined number of studies revealing information forlarge-scale shut photobioreactors. James and Al-Khars contemplated the development and the profitability of Chlorella and Nannochloropsis in a translucent vertical airdrop photobioreactor. They acquired productivities somewhere in the range of 109 and $264 \mathrm{~g} / \mathrm{m} 3 \mathrm{~d}$ for Nannochlropsis and somewhere in the range of 32.5 and $95.3 \mathrm{~g} / \mathrm{m} 3 \mathrm{~d}$ for the Chlorella strain. Miyamoto utilized a vertical glass tube with 5 $\mathrm{cm}$ breadth and $2.3 \mathrm{~m}$ stature $(4.5 \mathrm{~L})$. This is an air pocket segment unit with great light entrance. Its execution at full business scale-up still appears to be testing. The Monoraphidium efficiency in such reactor has been accounted for as $23 \mathrm{~g} / \mathrm{m} 3 \mathrm{~d}$. In these cylindrical kind photobioreactors, tube packs utilized as sun based illumination captors are made out of (a) polyvinylchloride (50 $\mathrm{mm}$ in measurement) or

3.2.1. (b) polycarbonate ( $32 \mathrm{~mm}$ in measurement). In some photobioreactors, the cylinders are wound spirals framing helical-rounded photobioreactors. As a rule, these kinds of reactors are appropriate for the way of life of microalgal species in nearness of daylight. Notwithstanding this, these frameworks in some cases require counterfeit enlightenment just as common light to improve the microalgae development. In any case, the acquaintance of fake light includes with creation costs, making the helical-cylindrical bioreactor just sufficient for the assembling of high-esteem included items. Another class of shut frameworks is the carrier photobioreactor. In this reactor, fluid movement is described by enormous circulatory flows in a heterogeneous stream system. Anderson and Eakins planned a rounded photobioreactor with the ability to deliver polysaccharides utilizing Porphyridium cruentum microalgae. The framework has a secluded plan, looking like a sunlight based authority with a photodetector set at a key area for rakish change of the glass surface position. The polysaccharide productivities distributed by the creators extended from 20 to $25 \mathrm{~g} / \mathrm{m} 2 \mathrm{dz}$.Carrier photobioreactor In transport photobioreactors, the liquid volume of the vessel is partitioned into two interconnected zones utilizing an astound or a draft tube. Fluid development is described by huge circulatory flows in the heterogeneous stream system. Transport photobioreactors are some of the time hard proportional up given their perplexing stream design. Vertical air pocket sections and carrier chambers can achieve considerably expanded spiral development of liquid, with high cycling of medium between the lighted and the dull zones. These reactor structures have a low surface/volume proportion. In any case, they can give a significantly more prominent gas hold-up than level reactors with a possibly more prominent isolated gas-fluid stream. Different analysts asserted that focal points for these units included

(a) high mass exchanges,

(b) good blending in with low shear pressure,

(c) low vitality utilization,

(d) relatively simple to work under sterile conditions,

(e) useful for the immobilization of green growth on moving particles.

In these units, societies experience the ill effects of photoinhibition and photograph oxidation, being liable to cycling impacts happening among lighter and darker zones. Constraints incorporate

(a) higher assembling and support cost,

(b) smaller light per unit surface zone,

(c) more refined development materials,

(d) higher shear weight on algal societies, and

(e) larger number of units are expected to assemble a business plant given the distance across to tallness can't be expanded altogether.

3.2.4. Flat plate photograph bioreactor Vertical plate photobioreactors blended via air foaming, appear to be surprisingly better than bubble segments as far as profitability and simplicity of activity. Level plate photobioreactors permit the accompanying:

(a) large illuminated surface zone,

(b) suitable for outside societies,

(c) good for green growth immobilization and

(d) good biomass productivities.

These photobioreactors are moderately modest and simple to clean. Vertical level plates can be suited in 1000-2000 L volume limit units that were effectively worked for long timeframes. In this manner, these are completely adaptable photobioreactor units. Shut level boards blended by foaming air can conceivably accomplish high by and large ground-elevated productivities as far as volume development. There are $500 \mathrm{~L}$ with $440 \mathrm{~L}$ culture volume limit units with $0.27 \mathrm{~g} / \mathrm{L} \mathrm{d}$ utilizing level fortified glass photobioreactor. Significant confinements incorporate

(a) difficulty of controlling society temperature,

(b) limited level of develop that the close to divider district, 
(c) possibility of hydrodynamic pressure, and

(d) algal strains are exposed to significant hydrodynamic anxieties.

These photobioreactors are reasonably unobtrusive and easy to clean. Vertical level plates can be fit in 1000-2000 L volume limit units that were viably worked for long time spans. As such, these are totally versatile photobioreactor units. Close level sheets mixed by frothing air can possibly achieve high all things considered ground-raised productivities to the extent volume advancement. There are $500 \mathrm{~L}$ with $440 \mathrm{~L}$ culture volume limit units with $0.27 \mathrm{~g} / \mathrm{L} \mathrm{d}$ using level sustained glass photobioreactor. Huge restrictions fuse

(a) difficulty of controlling society temperature,

(b) limited level of build up that the near divider region,

(c) possibility of hydrodynamic weight, and

(c) algal strains are presented to noteworthy hydrodynamic tensions.

Pulz depicted an upgraded enormous scope level plate photobioreactor module of $6000 \mathrm{~L}$. This twofold layer board $(8 \mathrm{~m} 2)$ is laid on the ground. One of the layers is utilized for the flow of the way of life, while the other is used for dissemination of the temperature-controlled water. Tredici and Tredici and Materassi built up a vertical alveolar board $(2.2 \mathrm{~m} 2)$ in view of a similar kind of material. Level boards can be utilized at variable equinoxial direction as for the sun's beams. Blending and deoxygenation procedures of the way of life suspension are influenced by constantly gurgling air at the base of the reactor. Tantamount plans with siphon and with carrier flow are additionally a work in progress. In all cases, high productivities were gotten given the high surface/volume proportion. Nonetheless, biomass yield could be restricted by photograph hindrance and temperature control issues.

\section{Schematic diagram of photosynthesis process}

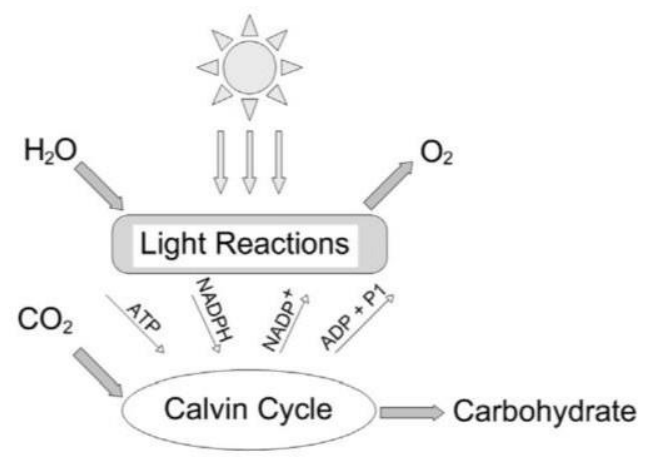

\section{ALGAE BIOMASS AS POTENTIAL RESOURCE FOR BIOFUEL.}

Green growth are enormous gatherings of photosynthetic oceanic living beings that comprise of two gatherings, microalgae and macroalgae, which are in unicellular structure and multicellular structure, separately. Both microalgae and macroalgae have chlorophyll as the key photosynthetic shade to fix climatic $\mathrm{CO} 2$ by means of photosynthesis, as earthly plants. Be that as it may, microalgae don't have stems, roots or leaves like earthbound plants while macroalgae does. Green growth can be found in a wide scope of natural surroundings, for example, ocean for marine green growth and streams, lakes, lakes and repositories for freshwater green growth. The development of green growth emphatically relies upon the encompassing temperature, measure of daylight and supplements. Algal biomass comprises of various advantageous mixes which are valuable in different markets. A wide decent variety of bioactive mixes like nutrients, steroids, proteins, polysaccharides, sugars and unsaturated fats created by green growth are by and large conceivably utilized in pharmaceutical, beauty care products and food ventures. In addition, against maturing, hostile to corpulence and cancer prevention agent properties displayed by green growth extricates are considered as a superior swap for engineered mixes. In addition, the high starch and lipid substance of green growth additionally assumes a key-job in sustainable power source creation as higher measure of vitality can be acquired from green growth contrasted with different biomasses. The upside of utilizing green growth as a feedstock for biofuel creation basically depends on the high profitability of green growth. Green growth have a lot higher development rates contrasted with earthbound plants and can finish an actual existence cycle in a couple of days. The lipid/oil content and the starch content that is utilized for the creation of biofuels is high in microalgae, now and then surpassing half, accordingly diminishing the prerequisite of different assets for the creation of same measure of oil/sugars. The development of green growth requires carbon dioxide, light and water for development, in which the carbon dioxide source required for green growth development can even be provided by fumes mechanical gases and this would in a roundabout way decrease ozone depleting substance discharges. Moreover, the utilization of green growth as feedstock doesn't incite land use changes and development of food crops stays unaffected. The ceaseless gracefully of feedstock for biofuel creation can be guaranteed if the green growth are developed utilizing set up techniques.

\subsection{Important composition of algae in biofuel production}

[18] Peter J, Williams B, Laurens ML. Microalgae, like all other living structures, are commonly made out of the significant concoction segments: lipids, sugars, proteins and nucleic acids. The particular substance of every one of this constituent is strain subordinate and can be intensely impacted by the way of life conditions utilized. Additionally, microalgae are considered as a rich wellspring of nutrients, minerals, enemies of oxidants as shades, and different mixes of pharmaceutical premium. During photosynthesis, the vitality changed over from daylight is put away as lipid or sugar inside the green growth, which is then removed from green growth for vitality gracefully. As of late, much scholarly and business examine have been done to assess strategies to build the lipid substance or vitality thickness of green growth biomass, particularly for microalgae, to improve the green growth based biofuel creation yield. It was discovered that the yield of lipid content is firmly identified with the complete yield of biomass, where the result of lipid content yield and biomass yield is the all out vitality yield got from the biomass. Exceptional 
returns of lipids and biomass can be acquired from microalgae when contrasted with different biomass, as the development time for microalgae is low. Green growth biomass will in general produce oil amount which is roughly multiple times more prominent than soybeans and 7 to multiple times more noteworthy than palm oil. Notwithstanding lipids, sugar is another basic segment of enthusiasm for bioenergy creation. Sugar in green growth has given an alternative to deliver biofuel, for example, bioethanol and bio-butanol. The sugar that goes about as the substrate in ethanol and butanol maturation is extricated from starch/cellulose present in green growth. The starch created by green growth is exceptionally fermentable in light of the low lignin content, which is appropriate for bioethanol creation. Green growth can store sugars as vitality saves in various structures, for instance, starch, cellulose, paramylon and laminarin. A large portion of the green growth have unbending, cellulose-fortified cell divider while sulfonated polysaccharides are found generally in red green growth that comprise of agarose and carrageenan. The sythesis of microalgae and macroalgae are portrayed in the accompanying segments.

Microalgae are green growth in tiny size which are just can be seen under the magnifying lens. The development of microalgae requires adequate measure of daylight, water (new water or seawater, relies upon sort of microalgae) and supplements, for example, carbon dioxide, nitrogen and phosphorus. The arrangement of microalgae fluctuates for various sort of species, as some may contain higher polysaccharides, or higher lipids content.

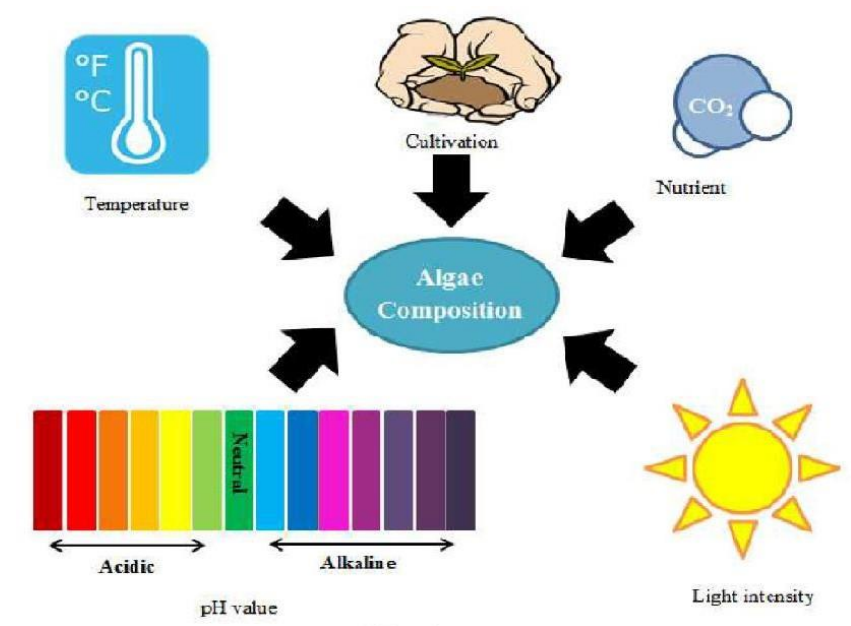

\subsection{Microalgae characterization}

It is essential to utilize a suitable feedstock to achieve high biofuel yields of pyrolysis. Biomass capacity in changing over to high estimation of biofuel is researched by deciding the essential investigation (carbon, hydrogen, oxygen, nitrogen and sulfur), biochemical structure, debris content, dampness content and higher warming worth (HHV) of biomass. Various investigations about portrayal of microalgae have been performed around the world. The summed up information to depict the piece and properties of microalgae dependent on reference information from various examinations are portrayed beneath. The essential investigation, biochemical arrangement and physical properties of some microalgae. Significant parts of microalgae are lipid, protein and sugar. Distinctive microalgae contain diverse measure of referenced significant segment. As it was referenced, basic investigation, debris content, dampness content and

HHV are resolved to explore transformation of microalgae to bio-oil. Bio-diesel get from lipids gathered in microalgae. Lipid, protein and sugars could be changed over to bio-oils. As indicated by Biller and Ross discoveries, biochemical sythesis of microalgae influences the bio-oil yield. Their outcomes demonstrated that bio-oil age follows the pattern lipids $>$ proteins $>$ carbohydrate. A lot of nitrogen heterocycles, pyrroles and indoles produce from protein; cyclic ketones and phenols produce from starches; unsaturated fats acquire from lipids.

HHV are determined to investigate conversion of microalgae to bio-oil. Bio-diesel obtain from lipids accumulated in microalgae. Lipid, protein and carbohydrates could be converted to bio-oils. According to Biller and Ross findings, biochemical composition of microalgae affects the bio-oil yield. Their results showed that bio-oil generation follows the trend lipids>proteins $>$ carbohydrate. Large amounts of nitrogen heterocycles, pyrroles and indoles produce from protein; cyclic ketones and phenols produce from carbohydrates; fatty acids obtain from lipids.

\section{THERMOCHEMICAL CONVERSION OF MICRO ALGAL BIOMASS}

[9] Amin S. In thermochemical process, common blends of biomass are decayed to bio-powers at raised temperature. This system gives a less intricate course to make bio-empowers, in relationship with manufactured and biochemical methodology. For example, an extra cleaning step required to refine the biomass before manufactured change process. On the other hand, biochemical change structures rely upon biocatalysts, for instance, mixes and microbial cells, despite warmth and manufactured mixtures. Other than hand, on occasion, a couple of days are required to complete the biochemical change reaction. Thermochemical structures offer progressively gainful choices since they rely upon heat and furthermore physical stimuli and they can be applied to a variety of biomass feed stocks. In this technique, usually there is no convincing motivation to incorporate engineered mixes and the reaction is developed in a short period of time. In this technique, warmth and manufactured reaction go about as two factors that impact things and essentialness improvement. Gasification, liquefaction, direct start and pyrolysis are the most notable subcategories of thermochemical change.

\subsection{Gasification}

Transformation of natural or fossil based carbonaceous mixes into engineered gases or syngas is named gasification. Regular gasification and supercritical water gasification are two unique courses to gasify microalgal biomass. The previous procedure, materials respond at high temperature $\left(800-1000^{\circ} \mathrm{C}\right)$ without burning with controlled measure of air, oxygen, argon, water or steam. Carbon monoxide, hydrogen, carbon dioxide and methane are the significant results of traditional gasification. This procedure has been monetarily grown, however warm yield of that is low more explicitly for when the biomass is wet. The supercritical water gasification process which did at lower temperature (375$\left.550{ }^{\circ} \mathrm{C}\right)$ and higher weight $(22-36 \mathrm{MPa})$ has higher warm yield, yet it has not been marketed at this point and it is immature. The working conditions and item piece in late models for ordinary and 
supercritical water gasification of microalgae. As it tends to be seen from the, the yield of these vaporous items is profoundly affected by temperature. Expanding the temperature improve $\mathrm{H} 2$ creation yield and reduction $\mathrm{CH} 4$ age. SWG (supercritical water gasification) materials respond at $400-500{ }^{\circ} \mathrm{C}$ and $24-36 \mathrm{MPa}$ in the nearness or nonappearance of impetuses. In this procedure, the major vaporous items are $\mathrm{H} 2, \mathrm{CO} 2$ and $\mathrm{CH} 4$. Temperature and impetus type are the working conditions that influence the yield of vaporous items.

\subsection{Liquefaction}

Biomass dampness substance could be diminished by utilizing ordinary dewatering strategies, for example, filtration and sedimentation can lessen the dampness substance of biomass to around 70-90\%. Thermochemical change of such biomass with high water content regularly requires a warm dewatering step preceding bio-fuel creation process. Bio-oil yield and its quality are profoundly relying upon the arrangement of microalgae. For example, Li et al. demonstrated that bio-oil yield for a high lipid and low protein microalgae is more than that of a high protein and low lipid microalgae. Then again, hydrocarbon substance of later microalgae was more than that of previous one.

In spite of the fact that this thermochemical change has higher vitality productivity in correlation with the other thermochemical strategies, reactors and prerequisites for referenced procedure are perplexing a direct result of the idea of procedure. This makes the procedure being increasingly costly in contrast with other thermochemical techniques..

\subsection{Direct combustion}

Biomass is scorched within the sight of abundance air through direct burning which is perhaps the easiest type of thermochemical dewatering step upgrades vitality cost. Thus, age of biofuels from microalgae will be less monetarily practical. Liquefaction is regarded to be another option and viable procedure to create bio-energizes from microalgal biomass with high dampness content. Liquefaction is a thermochemical transformation procedure to deliver fluid fills in high weight and temperature conditions. There is no compelling reason to dry the feedstock in this technique because of wet feed stocks used in liquefaction. The working states of microalgae liquefaction in certain examinations. As indicated by Table 5, temperature of liquefaction process fluctuates somewhere in the range of 200 and $350{ }^{\circ} \mathrm{C}$ in nearness or missing of impetus. Warming estimation of fossil oil is which is shut to that of bio-oil created from liquefaction of microalgae. It ought to be noticed that delivered bio-oil isn't appropriate for direct vitality creation. Be that as it may, it tends to be utilized as a sustainable feedstock for corefining in existing fossil-based treatment facilities process. In this procedure, vitality put away in the biomass through photosynthesis changes over to hot gases. Various biomasses could be expended as feedstock for this procedure, however their dampness content must be under half. Warmth or steam created by direct burning could be applied in family and modern applications or for power age. Referenced procedure is the fundamental technique to use biomass vitality, however it isn't considered as the primary procedure for age of vitality from microalgae. In spite of the fact that microalgae could be legitimately scorched, their produced vitality is low in examination with coal. Co-ignition of microalgae with coal is an elective procedure for manageable activity of microalgae. Coal ignition emanates $\mathrm{CO} 2$ to environment. Microalgae co-ignition may cause lower outflow of ozone depleting substances (GHG) into air.

\subsection{Pyrolysis}

[12] Xu D, Savage PE. . Biomass is warmed and disintegrated without oxygen or air by utilizing pyrolysis. In the pyrolysis of microalgae, the weight is normally climatic and the temperature is in the middle of 400 and $600^{\circ} \mathrm{C}$. In any case, at times the response temperature can be as high as $800^{\circ} \mathrm{C}$ and as low as $300^{\circ} \mathrm{C}$. A few examinations explored the pyrolysis of microalgal biomass. Bio-oil, roast and non-condensable gases are he significant results of microalgae pyrolysis. Microalgae properties, working condition and response type are parameters influencing the measure of referenced items. Li and et al. indicated that temperature improvement expands the gases yield and decay the burn yield consistently. They likewise indicated that $500{ }^{\circ} \mathrm{Cis}$ the ideal temperature to deliver the best return of bio-oil. Bordoli and et al. watched comparable pattern when they treat Scenedesmus dimorphus in a fixed bed. How the yield and substance creation of items could be influenced by temperature was researched by them. The impact of heterotrophic and autotrophic development of microalgae Chlorella protothecoides on the bio-oil yield had been explored by Miao and $\mathrm{Wu}$ by utilizing microalgae quick pyrolysis. They outlined that bio-oil yield delivered from quick pyrolysis of heterotrophic $(57.9 \%)$ cells was 3.4 occasions higher than that of autotrophic cells. In addition, oxygen substance, thickness and consistency of heterotrophic cells bio-oil was lower than that of autotrophic cells. Miao and et al. considered the pyrolysis of two various types of microalgae to portray the bio-oil yield and properties of pyrolytic oils. Bio-oil yield of Chllorella protothecoides and Microcystis aeruginosa was $17.5 \%$ and $23.7 \%$, individually. It ought to be referenced that they asserted a lot of microalgae hold fast to the reactor divider and doesn't respond totally which brought about a significant returns of singe and low yield of bio-oil.

\section{WASTE WATER TREATMENT}

6.1 Nutrition: Algae are significant bioremediation specialists. They are as of now being utilized by numerous wastewater offices. The potential for green growth in wastewater remediation is anyway a lot more extensive in scope than its momentum job. Microalgae contain higher nitrogen and phosphorus substance, around $10-11 \%$, individually, on a dry weight premise. These sorts of nitrogen and phosphorous levels are a few times more prominent than that of plants. Microalgae have likewise been utilized widely to expel overwhelming metals from wastewater despite the fact that these couldn't contend monetarily with particle trade tars. The utilization of microalgae has likewise stood out in light of the fact that microalgae can evacuate both $\mathrm{CO} 2$ and NOx during their development. Microalgae can likewise create, as expressed in the past segments, conceivably important biomass, which can be utilized as a creature feed added substance, slowdischarge manure and biodiesel feedstock.Microalgal

6.2. Nitrogen as nitrates and smelling salts is the most generally discovered nitrogen containing synthetic species. Ammonium is among the most widely recognized synthetic types of nitrogen that 


\section{International Journal of Engineering Applied Sciences and Technology, 2020 Vol. 4, Issue 12, ISSN No. 2455-2143, Pages 696-707 \\ Published Online April 2020 in IJEAST (http://www.ijeast.com)}

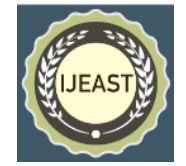

can be promptly consumed by microalgae. In this regard, a modest wellspring of nitrogen can be a utilized as a wastewater stream or as optional rewarded wastewater.

6.3. Phosphorous: Phosphorus is likewise a significant component required for cell development and microalgae digestion. Phosphorus is a basic component remembered for DNA, RNA and ATP, and cell film materials. In the photophosphorylation procedure, phosphorus is a fundamental component contributing as ATP. Subsequently, phosphorus accessibility has an enormous effect in microalgae development as it is significantly influenced in photosynthesis. Lipid gathering may happen in the way of life media under phosphorus starvation conditions. Phosphorus is normally accessible in the wastewater as inorganic anions species, for example, H2PO4 - and HPO4 2-.

6.4. Wastewater parts: Many types of microalgae are ready to successfully develop in wastewater conditions because of the plenitude of supplement inorganic species. A significant prerequisite for wastewater treatment (beside ooze expulsion by means of regular procedures, for example, enacted slime) is the need of evacuating high centralization of supplements. This is valid specifically for nitrogen $(\mathrm{N})$ and phosphorus (P) species. Not doing so prompts eutrophication with supplements aggregation in waterways, lakes or lakes.

6.5. Anaerobic processed dairy squander water treatment: Treatment of domesticated animals effluents is accepting expanding consideration. Biogas is inferred through an oxygen consuming absorption of biomass, for example, creature squanders, metropolitan waste water, and land-fill squander. Anaerobic assimilation is the microbially interceded bio-synthetic corruption of complex natural material into straightforward organics and broke down supplements. Digesters are physical structures that encourage a vigorous absorption by giving an anaerobic situation to the life form dependable fordigestion. Processing domesticated animals fertilizer through a vigorous digesters catches methane, which can be utilized as a vitality source while lessening discharges of this ozone depleting substance.

6.6. Municipality wastewater treatment: Water utilized in our everyday life goes down the channel and into the sewage domiciliary assortment framework. This waste water is regularly assigned as civil wastewater. This incorporates water from showers, showers, sinks, dishwashers, clothes washers, toilets and others. Private ventures and enterprises situated in the urban regions likewise regularly contribute with a lot of wastewater to sewage assortment frameworks. Frequently, enormous enterprises treat their own modern wastewater. The biochemical oxygen demand (BOD) and the total suspended solids (TSS) load in industrial wastewaters. Industrial wastewaters contain heavy metal such as cadmium, chromium, zinc and others. Furthermore, they contain organic chemical toxins such as hydrocarbons, biocides and surfactants. Effluents from textile, leather, tannery, electroplating and other metal processing industries have considerable amounts of toxic metal ions. These types of toxic elements are both harmful to the ecosystem and unsafe for humans. The conventional methods of industrial wastewater treatment involve precipitation, ion exchange, electro winning (electroextraction) and electrochemical methods.

[21] Ho S-H, Chen C-Y, Chang J-S. Due to generally low nitrogen and phosphorous concentrations and high toxin levels, algal growth rates are lower in many industrial wastewaters while compared with their growth in municipal domiciliary wastewaters .Consequently, there is less potential for utilizing industrial wastewaters for algal culture. Industrial wastewaters contain chemicals and pigments. These wastewaters also contain metals, Pand $\mathrm{N}$, at low concentrations and are able to support algal growth with B. braunii and Chlorella saccharophila, and a marine alga Pleurochrysis carterae.

\section{ALGAE GROWTH/CULTIVATION}

Moreover, the maximization of the algal productivity also implies optimizing algae culture; minimizing $\mathrm{CO}_{2}$ capture and wastewater treatment. One of the major issues in the industrial scale-up of micro algae culture is related to algae culture in open ponds under uncontrolled conditions. It is only recently that closed biosectors have been considered complementary to algal mass culture in open systems. The following are the key aspects of the closed system reactor deign: (i) light source and orientation; (ii) algae circulation (iii) materials of construction, (iv) $\mathrm{CO}_{2}$ feed and $\mathrm{O}_{2}$ removal and (v) $\mathrm{pH}$ and temperature control.

\section{PERSPECTIVE AND CHALLENGES}

The aqueous liquefaction of green growth, along with the aqueous updating of bio rough, is a promising innovation for bio-oil creation from green growth biomass. In any case, the subsequent bio unrefined contains various heteroatoms (i.e., $\mathrm{O}, \mathrm{N}$ and $\mathrm{S}$ ), of which the $\mathrm{O}$ and $\mathrm{N}$ components involve a huge extent. Oxygen itself has no warming worth, and nitrogen and sulfur will cause ecological contamination during bio oil burning [66]. Albeit appropriate impetus use has notably decreased the heteroatom content and improved bio rough quality, a definitive bio unrefined item despite everything can't fulfill biodiesel guidelines and needs further deoxygenation, denitrogenation and desulfurization. Subsequently, it is important to additionally enhance reactant hydrotreating conditions (e.g., utilizing progressively successful impetuses) to expel more $\mathrm{N}, \mathrm{O}$ and $\mathrm{S}$ heteroatoms. In any case, the synergist systems with respect to green growth HTL and bio rough overhauling are just mostly settled, and along these lines examining the reactant component and growing increasingly proficient impetuses stay basic for impetus structure streamlining and the ensuing industrialization of the full procedure.

It is essential to recoup and reuse impetus after green growth HTL and biocrude redesigning, particularly if the impetus is costly. Saber consumed the strong buildup from the synergist HTL analyze in a heater at $550{ }^{\circ} \mathrm{C}$ for $2 \mathrm{~h}$, and afterward isolated the nano-Ni/SiO2 impetus from the debris utilizing a strainer. Nonetheless, this recuperation is troublesome in light of the fact that $62 \%$ and $18 \%$ of the first nano-Ni/SiO2 are recouped in the first and second reusing endeavors, individually, and none is recuperated in the third reusing exertion because of the decrease of the molecule size. The recuperated impetus is then utilized in the HTL of Nannochloropsis. At $210{ }^{\circ} \mathrm{C}$, prompting a lower bio-oil yield contrasted with the first impetus owing with the decrease of the mass and deactivation of the recuperated impetus. Another recuperation approach is to restore the 
blend of the debris and catalystparticles to the reactor in the wake of consuming the strong buildup. This recuperation approach (no partition of the debris and impetus) recommends that reusing the impetus 2 or multiple times and can diminish the financial weight of the impetus for the whole procedure and is all the more encouraging that the principal approach referenced previously. $\mathrm{Pt} / \gamma-\mathrm{Al} 2 \mathrm{O} 3$ assumes various jobs, for example, hydrogenation (hydrodenitrogenation, hydrodeoxygenation or hydrodesulfurization) and deoxygenation (decarboxylation or decarbonylation) in the redesigning of algal biocrude under aqueous conditions. In any case, its surface zone diminishes essentially (around 60\%) after the impetus is reused multiple times in the algal bio unrefined overhauling at $400{ }^{\circ} \mathrm{C}$ for $1 \mathrm{~h}$ within the sight of $\mathrm{H} 2$ likely because of coke testimony. Directly, the current research in regards to impetus recuperation and impetus deactivation in green growth HTL and bio rough overhauling is scant.

In this way, it is critical to grow further developed impetus recuperation and recovery strategies dependent on a profound comprehension of the strong item properties and impetus deactivation instruments engaged with aqueous conditions. Reactant green growth HTL experiences a few restrictions, for example, potential nitrogen harming of biocrude for the impetus, powerlessness to fouling in the nonstop HTL activity by a heterogeneous impetus, and choice of an effective impetus type. Alongside great reactant impacts, high security and a long assistance life are additionally significant parts of impetus determination. In spite of the fact that it appears that multi-part impetuses are increasingly reasonable for bio-oil creation from green growth HTL, they presumably will confront issues with respect to the solidness, lifetime and cost. So also, hydrotreatment is a promising methodology yet more endeavors are required to determine the issue of coking and impetus deactivation. The consolidated impact of steam from oxygenates parchedness and massive unsaturated hydrocarbons from oligomerization responses is accounted for to be answerable for quick impetus deactivation during the updating of algal bio rough into energizes grade hydrocarbon mixes. The consolidated impact of steam from oxygenates lack of hydration and cumbersome unsaturated hydrocarbons from oligomerization responses is accounted for to be liable for fast impetus deactivation during the redesigning of algal bio unrefined into fills grade hydrocarbon mixes. By and by, the distributed examinations on synergist green growth HTL and bio rough overhauling principally essentially center around growing exceptionally productive impetuses and assessing reactant impacts in generally short test times (basically test times of a few hours) in seat scale group reactors.

The investigations concerning the impetus dependability and recovery related with impetus financial matters in green growth HTL and bio rough updating stay scant. As far as anyone is concerned, there is no exhaustive data on the venture or working expense of synergist green growth HTL and biocrude updating. In this manner, the examination on exceptionally productive impetuses having higher dependability, longer assistance lives and lower costs is additionally significant. The home occasions of the green growth HTL and the synergist redesigning of biocrude are still generally long, and the overhauling temperature is very high too. This pattern will unavoidably contrarily influence the speculation and working expenses of biocrude creation from green growth because of the huge reactor ability and the huge measure of vitality utilization. Growing much better impetuses can be required to decrease the response temperature and time for green growth HTL and its biocrude redesigning. Thusly, it is fundamental to comprehend the synergist response energy in these aqueous change forms because of the varieties in algal biomass and trial conditions. In addition, green growth HTL commercialization is confronting different difficulties, for example, a low productivity of warmth move and recuperation for the HTL factor, a low yield of biocrude, poor fuel properties of biocrude, for example, destructiveness, a high nitrogen content, trouble with overhauling, and absence of compelling utilization of HTL side-effects, for example, solids and the watery stage. Thus, the further enhancement of working parameters, office and framework plan, and result recuperation and use, and even the development of biocrude refining techniques stay pivotal in this field.

During the constant enormous scope creation of green growth HTL, it is increasingly fitting to utilize the dissolvable free technique (e.g., attractive energy and centrifugation activity) to acquire waterinsoluble biocrude, yet dissolvable extraction or further developed methods for a little bit of water-solvent biocrude accounts for $<10$ wt $\%$ of the all out biocrude. These two assortments of biocrudes are altogether unique in yield and quality as referenced previously. In this way, independently gathering and redesigning water-insoluble biocrude and water-solvent biocrude is most likely superior to fundamentally gathering and overhauling the absolute biocrude (water-insoluble biocrude in addition to water-dissolvable biocrude), yet significant research is very scant and the subject requires profound investigation.

Until this point in time, the green growth HTL process has been transformed from the condition of applied research to little scope prototyping; along these lines creating pilot-scale plants with enormous scope reactors is required for the HTL procedure. Be that as it may, albeit a few research bunches have explored the persistent response frameworks of green growth HTL, by and by, there is no business working gadget for green growth HTL. It stays hard to make a nonstop business activity for persistent synergist green growth HTL and biocrude updating.

A portion of the issues are as per the following:

1) it requires an impetus with high security and a long help life;

2) how to guarantee the persistent framework activity in occasional impetus substitution; and

3) the reusing innovation for the impetus must be set up to keep up great framework financial aspects.

Prominently, in the enormous scope reactor plan, a rounded reactor is progressively helpful for the commercialization of the nonstop HTL process. An impetus or a quick warming technique can be acquainted with limit the arrangement of roast and coke in the reactor. The warmth move framework structure for a huge scope reactor is hard to work because of the low warmth move coefficient of the feedstock and the variety of the enthalpy of HTL responses. 


\section{International Journal of Engineering Applied Sciences and Technology, 2020 \\ Vol. 4, Issue 12, ISSN No. 2455-2143, Pages 696-707 \\ Published Online April 2020 in IJEAST (http://www.ijeast.com)}

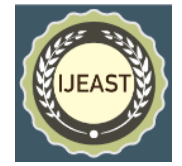

Different obstructions, for example, heat recuperation, consumption in the reactor, strength of the item, and salt precipitation ought to be considered in the HTL reactor structure. Research should concentrate on the HTL creation process for an enormous scope; nonetheless, a few primary difficulties must be settled, including green growth strain determination, high-caliber and feasible green growth creation frameworks, a ceaseless HTL process improvement, the HTL yield increase for maintainable financially savvy advances, and the all encompassing streamlining of bio treatment facility forms. In general, the examination on synergist green growth HTL and biocrude redesigning ought to essentially take the accompanying headings: investigating the catalytic mechanisms of catalytic algae HTL and bio crude upgrading to develop high efficiency in catalysts,

1) investigating the deactivation properties, recuperation and recovery strategies, and performing monetary assessments of impetuses to understand a long lifetime and savvy impetus application,

2) investigating the recuperation, use and enhancement of vitality and items to ensure a decent monetary benefit,

3) developing a propelled indispensable procedure for synergist green growth HTL and bio unrefined redesigning,

4) optimizing working parameters, office and framework structure, and

5) designing enormous scope ceaseless reactor frameworks utilizing an impetus.

\section{CONCLUSION}

HTL is a promising development for changing over green development into bio grungy and catalysts accept a basic activity in green development HTL and the resulting bio unpleasant updating. The yield and nature of biocrude are incredibly dependent upon the stimulus type, reaction temperature, reaction air (e.g., with or without H2), driving force stacking, etc. In green development $\mathrm{HTL}, \mathrm{Ni} / \mathrm{SiO} 2-$ Al2O3, Ni-Mo/Al2O3, Pt/C, Pt/Al2O3 and Ce/HZSM-5 show incredible synergist execution in improving the biocrude quality. Ce/HZSM-5, Co/Mo/Al2O3 and Ni/SiO2$\mathrm{Al} 2 \mathrm{O} 3$ have the most raised activities for reactant denitrogenation, deoxygenation and desulfurization, independently. In particular, the Ce/HZSM-5 catalyst is apparently the best option for improving the idea of biocrude from green development HTL at present. The maintained $\mathrm{Ru}$ catalyst (e.g., $\mathrm{Ru} / \mathrm{C}$ or $\mathrm{Ru} / \mathrm{C}+$ alumina) shows high deoxygenation, denitrogenation and hydrogenation practices in biocrude redesiging. The $\mathrm{Pt}$ stimulus (e.g., $\mathrm{Pt} / \mathrm{C}$ and $\mathrm{Pt} / \gamma$ $\mathrm{Al} 2 \mathrm{O} 3)$ has extraordinary reactant execution in diminishing the heteroatom content and extending the biocrude quality in green development HTL and biocrude updating, particularly for synergist hydrogenation, deoxygenation and denitrogenation. Green development HTL and biocrude upgrading incorporate complex reactions, and each driving force likely decidedly influences steps in the reactions. It is routinely illogical to extraordinarily improve the yield and nature of biocrude at the same time just by a singular section catalyst. Productive multi-part impetuses for green growth
HTL and biocrude redesigning must be created to diminish the response temperature and habitation time to guarantee the yield and nature of the biocrude. Building up an impetus with higher movement and steadiness, a more extended lifetime and lower cost dependent on profound reactant component investigation stays vital. In addition, separately gathering and redesigning water-insoluble bio rough and water-solvent bio unrefined gives off an impression of being a superior methodology than indispensably rewarding them.

\section{ACKNOWLEDGEMENT}

We are over helmed in all humbleness and appreciation to recognize our profundity to every one of the individuals who have helped me to put these thoughts, well over the degree of effortlessness and into something concrete.

We are exceptionally obligated to Project associate Mr. Shivendra Nandan and Mr. Rishikesh Trivedi for their survey investigate work and steady help just as for giving vital data in regards to the task and additionally for their help in finishing the venture.

\section{REFERENCES}

[1] Chisti Y. 2007. Biodiesel from microalgae. Biotechnol Adv;25:294-306.

[2] Posten C, Schaub G. 2009 Microalgae and terrestrial biomass as source for fuels-a process view. J Biotechnol;142:64-9.

[3] Behrendt F, Neubauer Y, Oevermann M, Wilmes B, Zobel N. 2008. Direct liquefaction of biomass. Chem Eng Technol;31:66777.

[4] Kishimoto M, Okakura T, Nagashima H, Minowa T, Yokoyama S, Yamaberi K. 1994. CO2 fixation and oil production using microalgae. J Ferment Bioeng;78:479-82.

[5] Brennan L, Owende P. 2010. Biofuels from microalgae-A review of technologies for production, processing, and extractions of biofuels and co-products. Renew Sustain Energy Rev;14:557-77.

[6] Anastasakis K, Ross AB. Hydrothermal liquefaction of the brown macro-alga Laminaria Saccharina: effect of reaction conditions on product distribution and composition. Bioresour Technol;102:4876-83.

[7] Patil V, Tran KQ, Giselrod HR. 2008. Towards sustainable production of biofuels from microalgae. Int J Mol Sci;9:1188-95.

[8] Tsukahara K, Sawayama S. 2005. Liquid fuel production using microalgae. J Jpn Petrol Inst;48:251-9.

[9] Amin S. 2009. Review on biofuel oil and gas production processes from microalgae. Energy Convers Manag;50:1834-40.

[10] Saber M, Nakhshiniev B, Yoshikawa K. 2016. A review of production and upgrading of algal bio-oil. Renew Sustain Energy Rev;58:918-30.

[11] Arvindnarayan S, Prabhu KKS, Shobana S, Kumar G, Dharmaraja J. 2017. Upgrading of micro algal derived bio-fuels in thermochemical liquefaction path and its perspectives: a review. Int Biodeterior Biodegrad;119:260-72.

[12] Xu D, 2014. Characterization of biocrudes recovered with 
and without solvent after hydrothermal liquefaction of algae. Algal Res;6:1-7.

[13] Yanayi M, Watanabe Y, Saiki H. 1995. CO2 fixation by Chlorella sp.HA-1 and its utilization. Energy Conversion and Management;36(6-9):713-36.

[14] Miron AS, Garcia MC, Gomez AC, Camacho FG, Grima EM, Chisti Y. 2003. Shear stress toleranceand biochemical characterization of Phaeodactylum tricornutum inquasi steady- state continuous culture in outdoor photobioreactors. Biochemical Engineering Journal;16:287-97.

[15] Yun YS, Lee SB, Park JM, Lee CI, Yang JW. 1997. Carbon dioxide fixation by algal cultivation using wastewater nutrients. Journal of Chemical Technology and Biotechnology;69:451-5.

[16] Campbell BJ, Engel AS, Porter ML, Takai K. 2006. The versatile $\varepsilon$-proteobacteria: key players in sulphidic habitats. Nature Reviews Microbiology;4:458-68.

[17] Peter J, Williams B, Laurens ML. 2010. Microalgae as biodiesel and biomass feedstocks \& analysis of the biochemistry, energetics and economics. Energy \& Environmental Science;3:554-90.

[18] Raven H, Peter H, Ray F, Eichhorn SE. 2006. Biology of plants. 7th ed. New York: W.H. Freeman and Company Publishers; 124-7.

[20] Costa JA, Colla LM, Duarte PF. 2004. Improving Spirulina platensis biomass yield a fed-batch process. Bioresource Technology;92:237-41.

[21] Ho S-H, Chen C-Y, Chang J-S. 2012. Effect of light intensity and nitrogen starvation on $\mathrm{CO} 2$ fixation and lipid/carbohydrate production of an indigenous microalga Scenedesmus obliquus CNW-N. Bioresource Technology; 113: 244-52. 